\title{
1 Increased genetic contribution to wellbeing during the 2 COVID-19 pandemic
}

4 C.A. Robert Warmerdam ${ }^{1}$, Henry H. Wiersma ${ }^{1}$, Pauline Lanting ${ }^{1 *}$, Lifelines Corona Research

5 Initiative, LifeLines Cohort Study, Marjolein X.L. Dijkema ${ }^{1}$, Judith M. Vonk², H. Marike Boezen²,

6 Patrick Deelen ${ }^{1,3}$, Lude H. Franke ${ }^{1,3}$

$7 \quad{ }^{1}$ Department of Genetics, University Medical Center Groningen, University of Groningen, Groningen,

8 The Netherlands

$9{ }^{2}$ Department of Epidemiology, University Medical Center Groningen, University of Groningen,

10 Groningen, The Netherlands

$11{ }^{3}$ Oncode Institute, Utrecht, The Netherlands

$12 *$ Shared first authors

13 Abstract

Physical and mental health are determined by an interplay between nature, i.e. genetics, and nurture, which encompasses experiences and exposures that can be short or long-lasting. Depressive episodes, for example, are partly the result of an interaction between stressful life-events and a genetic predisposition to depression The COVID-19 pandemic represents a unique situation in which whole communities were suddenly and simultaneously exposed to both the virus and the societal changes required to combat the virus. We studied 27,537 population-based biobank participants for whom we have genetic data and extensive longitudinal data collected via 19 questionnaires over 10 months, starting in March 2020. This allowed us to explore the interaction between genetics and the impact of the COVID-19 pandemic on individuals' wellbeing over time. We observe that genetics affected many aspects of well-being, but also that its impact on several phenotypes changed over time. Over the course of the pandemic, we observed that the genetic predisposition to life 
satisfaction had an increasing influence on perceived quality of life. These results suggest that people's genetic constitution manifested more prominently over time, potentially due to social isolation driven by strict COVID-19 containment measures. Overall, our findings demonstrate that the contribution of genetic variation to complex phenotypes is dynamic rather than static.

\section{Main text}

30 To explore the role of genetics in individual's experiences of the COVID-19 pandemic, we studied the 31 impact of genetic variation on physical and mental health and lifestyle behaviours in the Lifelines

32 biobank, a prospective follow-up cohort study of 167,000 participants living in the three northern provinces of the Netherlands. In March 2020, just four weeks after the COVID-19 pandemic reached the Netherlands, we began sending out questionnaires to track infections and wellbeing in this cohort (9). These repeated questionnaires allowed us to longitudinally track physical and mental health, and we report here on results for the 19 questionnaires sent over the first 10 months of the project (Fig. 1, Table S1, Table S2). In total, we had genotype data for 27,537 participants of whom 17,831 had completed at least one questionnaire during the first half of the study period and at least one questionnaire during the second half of our study (Fig. S1). The 17,831 participants with longitudinal data completed on average 13 questionnaires. We used the genetic data to calculate 17 polygenic scores (PGSs) for each participant based on summary statistics of genome-wide association studies (GWASs) for BMI (10), COVID-19 susceptibility and severity (11), educational attainment (12), life satisfaction (13), personality traits $(14,15)$, behavioural traits $(16-18)$ and psychiatric diseases (19-22) (Table S3, Fig. S2). 
a) lifelines:

Prospective follow-up cohort study in 167,000 participants, living in the three northern provinces of the Netherlands

(Friesland, Groningen, Drenthe)

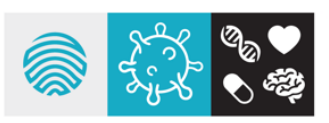

Lifelines Corona Research

Lifelines COVID-19

questionnaire

research focuses on:

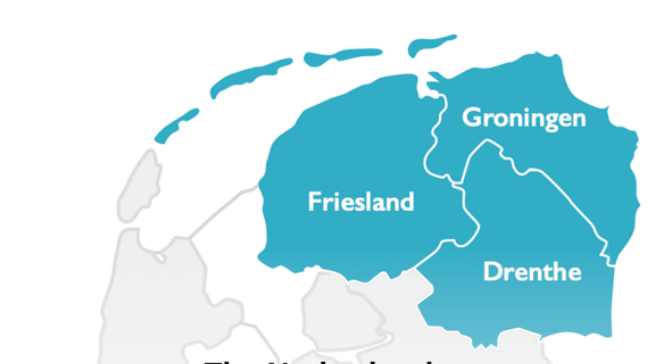

The Netherlands

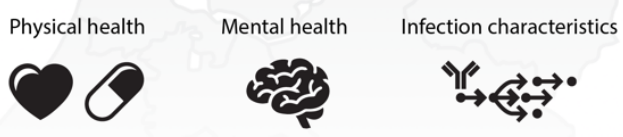

19 questionnaires (March 2020 - January 2021)

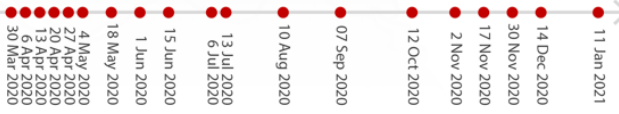

b)

\section{7,537 participants genotyped on Global Screening Array (GSA) or HumanCytoSNP}

$\mathbf{\Omega} \rightarrow \mathbf{\Omega} 17,831$ participants with longitudinal data

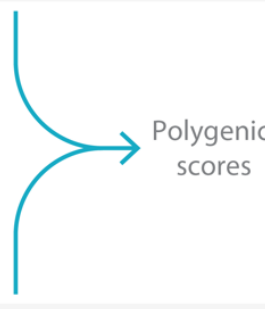

c)

Traits with GWAS summary statistics
for calculating polygenic scores

General phenotypes:

BMI

COVID-19 susceptibility

COVID-19 severity

Educational attainment

Life satisfaction

Personality traits:

Neuroticism

Anxiety/tension

Worry/vulnerability

Behavioural traits:

Physical activity

General risk tolerance

Tobacco and alcohol use

Psychiatric diseases:

Schizophrenia

Obsessive compulsive disorder

Depression

Autism
믐 19 questionnaires

(March 2020 - January 2021)

$\mathbf{\square} \rightarrow \mathbf{\square} \quad 288$ tested questionnaire items
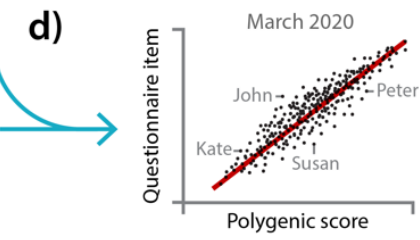

$\checkmark$

e) Study temporal aspect of polygenic score correlations

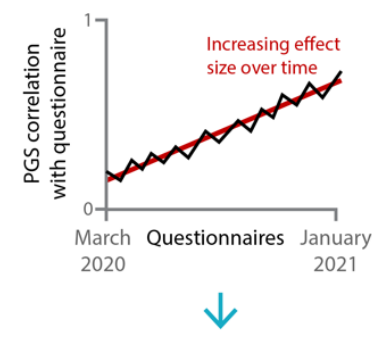

Model polygenic score interactions in longitudinal mixed effects model

Fig. 1: Overview of the Lifelines COVID-19 cohort.

47 a) Our study is based on the Lifelines prospective follow-up cohort study and the accompanying COVID-19 questionnaire research in which we sent out repeated questionnaires. b) We used 27,537 participants for whom we have genotype data available. c) Using the results of genome-wide association studies, we calculated polygenic scores (PGSs) for 17 traits. d) Questionnaire items can in part be explained by the PGSs. e) Repeated 
questionnaire items allow us to study the temporal variation in the contribution of genetics to each of the 46 questionnaire outcomes using a longitudinal mixed-effects model.

We then performed a baseline association analysis between the 17 PGSs and the responses to 288 questionnaire items (Table S4) and observed 302 Bonferroni-corrected significant associations for 143 unique questionnaire items (Fig. 2, Table S5, Fig. S3) (Bonferroni-corrected $\alpha \leq 0.05$ ). This indicates a genetic influence on the features measured by these questionnaire items, which covered aspects of mental health, attitudes towards pandemic public health measures, COVID-19 exposures and cases, and physical health. For instance, we observe that high PGSs for neuroticism, schizophrenia and depression are negatively associated with questionnaire items about personality traits, health complaints, fatigue and exhaustion (i.e. and Neuroticism-PGS and "felt nervous", pvalue $=1.88 \times 10^{-23} ;$ Neuroticism-PGS and "felt tired quickly", $p$-value $\left.=2.65 \times 10^{-16}\right)$, whereas we saw the opposite direction of association for the Life satisfaction where a high PGS is associated with lower "chest pain" scores $\left(p\right.$-value $\left.=4.48 \times 10^{-10}\right)$. Life satisfaction and neuroticism are also, respectively, negatively and positively associated to other health complaints and wellbeing items (i.e. Life satisfaction PGS and "excessive worrying", p-value $=1.29 \times 10^{-14}$; Life satisfaction PGS and "quality of life"; $p$-value $\left.=8.13 \times 10^{-14}\right)$. The observation that people with a high genetic burden for psychological traits score lower on wellbeing related questions is in concordance with previous literature (23-25). There are also PGSs that are significantly associated to the outcomes of several COVID-19-related questions. For instance, we observe many significant associations between the PGS for Educational attainment and variables pertaining to COVID-19 developments, including opinions about these developments (e.g. "having trust in the government's response to the COVID-19 pandemic"; p-value $=1.05 \times 10^{-9}$ ) and public health measures (e.g. "not shaking hands"; $p$-value $=6.39 \times 10^{-7}$ ). Furthermore, we observed positive associations between: the PGS for Worry/Vulnerability and "worry about infecting someone else" ( $p$-value $=2.41 \times 10^{-6}$ ) and between the PGS for Alcohol consumption and "whether or not individuals avoid facilities like bars and restaurants as a COVID-19 
81 the COVID-19 pandemic were at least partially driven by their genetic predispositions, as reflected in

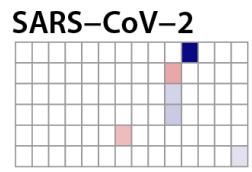

Ever positive SARS-CoV-2 PCR test

Doing every possible thing to help those who are infected

Has someone close with COVID-19

Having quarantined or gone into (self-)isolation during second wave

Expecting others to help me after infection

\section{Adherence to COVID19 restrictions}

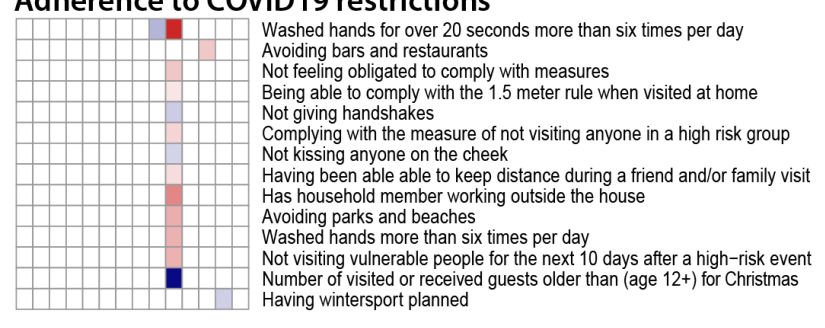

\section{COVID19-related sentiments}

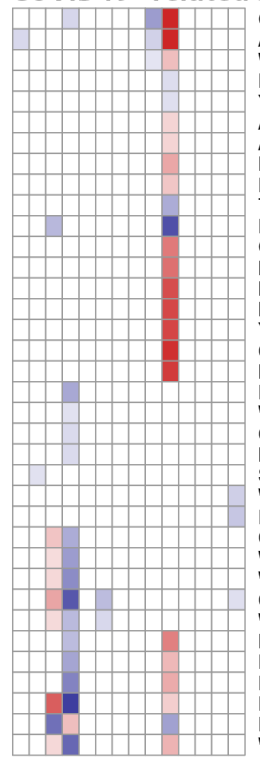

Government must act tougher to reduce number of infections

Afraid that important ground rights will be more easily ignored in future Worried about there being a shortage of medication

Expecting resurgence of coronavirus due to christmas holidays

Young people can do whatever they want if they keep enough distance Appreciating social distancing in general

A pre-defined roadmap for the corona measures gives peace of mind

Face masks laying around on the street and in nature are problematic

The government, listening to scientists, is important for the corona policy Reduced usual healthcare, enabling care of COVID-19 patients is justified Being bothered not take economic interests sufficiently

More people die indirectly due to coronacrisis than directly due to COVIDMeasures must be taken to reduce infections among young people Young people shoud be addressed as group to comply with measures Companies should be protected from going bankrupt at all cost Money for financial support should be spend to improve healthcare Worried about losing jo

Concerned about not beeing able to see friends and family Being bothered by people that do not wear a facemask Society is in a crisis

Willingness to comply longer to the measure of not giving handshakes It is important to watch COVID-19 press-conferences Concerned about financial trouble

Worried about long duration before life returns to normal Worried about someone close getting sick

Worry about infecting someone pan

Perceiving others as a threat to personal well-being

Estimated chance to infect someone else

Estimated chance to become infected

rustrated with how things go in

Having faith in the response of the government to COVID-19

\section{COVID19 vaccine sentiments}

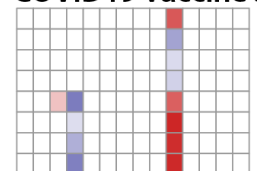

Thinking that a corona vaccine will have serious side effects Willingness to get vaccinated if I may adhare less strict to the measure Being relieved about there being a vaccine

Finding the corona vaccine scary

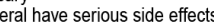
Ben vaccination

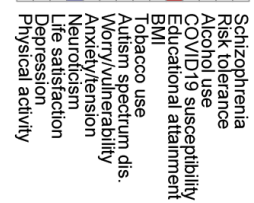

\section{Physical health}

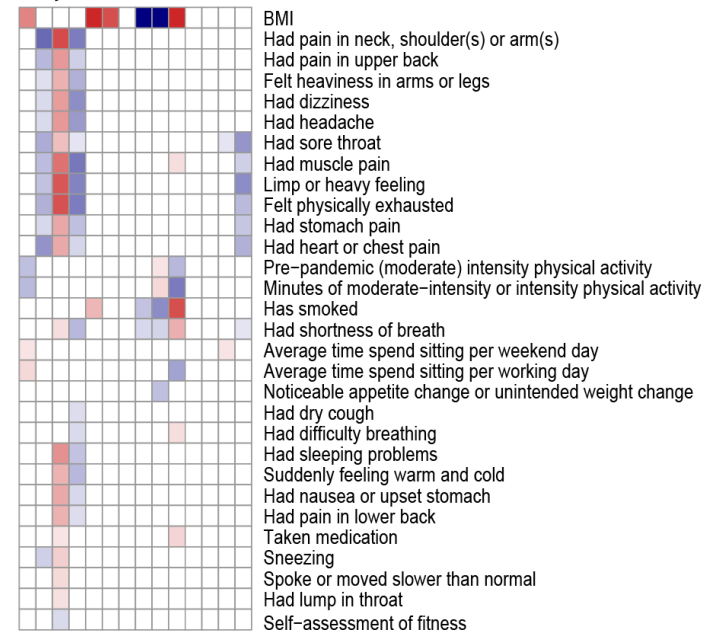

\section{Mental health}
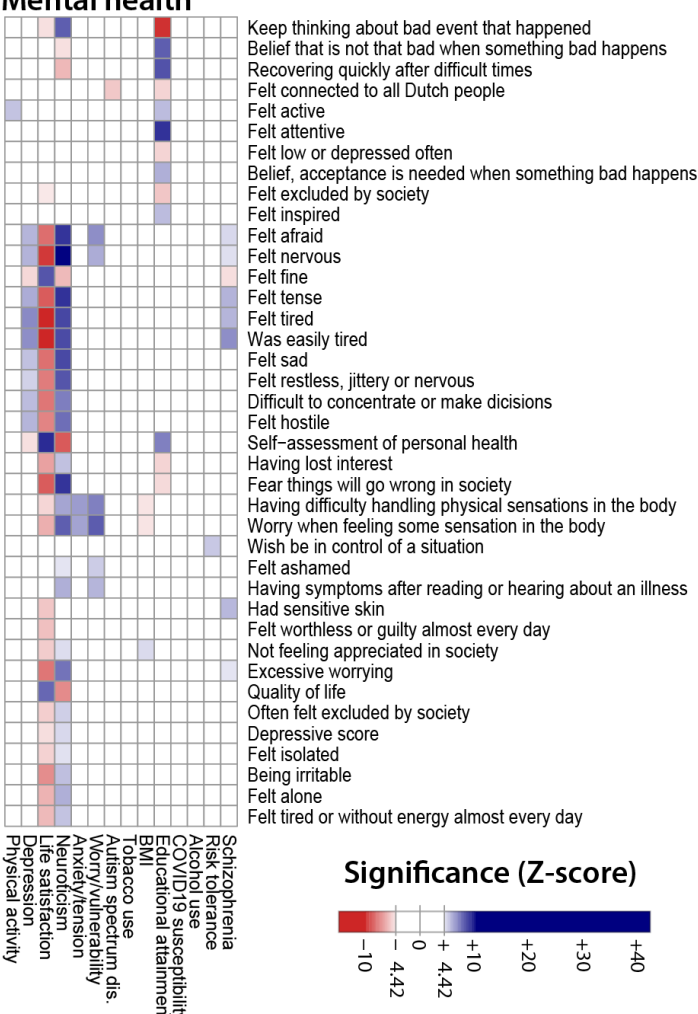
Fig. 2: Significant associations of PGSs and question answers at baseline.

A Z-score heatmap highlighting significant associations between questionnaire outcome items and polygenic scores. In total, we analysed 288 questionnaire items and questionnaire-derived items, of which 143 have a significant association with at least one PGS. We observe significant associations of the PGSs for depression, life satisfaction, neuroticism and schizophrenia with wellbeing. Additionally, COVID-19 sentiments are associated to PGS traits including educational attainment, neuroticism and worry/vulnerability. Associations were estimated between PGS and outcome items using a multivariate model (linear, logistic, or ordered logistic regression) with age, sex, household size, having children and having chronic disease used as covariates. The 'Ever positive Sars-Cov-2' item was determined from answers to all questionnaires. for all other items we used the first time the question was asked. We used two PGSs related to physical activity (Accelerometer-based physical activity \& Moderate to vigorous physical activity) for clarity we used the maximum Z-score of the two PGSs for the physical activity column in this figure.

Most GWASs are conducted at a single point in time and identify a static relationship between genetics and a trait. Due to the synchronized and prolonged exposure of the COVID-19 pandemic we were able to determine if this genotype-phenotype relationship can change over time. To do so we performed longitudinal analyses using mixed-effect models for 46 PGS-question pairs that had a significant baseline association and that have been asked at multiple timepoints (Table S6). Fourteen of these showed a time dependent effect at nominal significance $(P \leq 0.05)$. At a false-discovery rate (FDR) of 0.05, 11 PGS-question pairs showed a significant time dependent effect (including polygenic scores for Life satisfaction, Neuroticism, Depression, Schizophrenia, and COVID-19 susceptibility, Fig. S4, Table S7, Note S1), of which 2 were Bonferroni significant (genetic predisposition of COVID-19 susceptibility with a positive SARS-CoV-2 PCR test and polygenic score for life satisfaction with tiredness). To rule out that these observed effects are caused by attrition bias we also performed analyses on a subset of samples who had completed questionnaires at 1, 4, 7 and 10 months (Note S2, Table S8, Fig. S5). 
We found that the PGSs for Life satisfaction, Neuroticism and Depression affected 5 correlated outcomes related to wellbeing (Fig. S4, Table S7). We observed time-dependent effects for "perceived quality of life", "feeling good", "was easily tired", "feeling tired" and "feeling physically exhausted". Since the PGSs of these traits, as well as the answers to the questions, are either positively or negatively correlated to each other (Fig. S1, Fig. S6, we assume that this is a single effect. In the interest of clarity, we focus our discussion below on the effect of the Life satisfactionPGS on "perceived quality of life".

The mean perceived quality of life varied over time, with a peak during the summer of 2020 that was likely due to summer holidays and warm weather but also because COVID-19-related restrictions and infections were at a minimum (Fig. 3, Fig. S7, Fig. S8, Table S9). As expected, we observed that the PGS for Life satisfaction is positively associated with "perceived quality of life" (p-value: $8.13 \times 10^{-}$ $\left.{ }^{14}\right)$.

What is intriguing is that the effect of the PGS for Life satisfaction on the perceived quality of life increased across the pandemic ( $p$-value: $3.1 \times 10^{-3}$ ) (Fig. 3). At the end of the summer, the mean perceived quality of life started to decline, but participants with a high Life satisfaction-PGS appear to be more resilient and reported smaller decreases in quality of life, while participants with a low PGS reported a stronger decrease in their reported quality of life. This shows that genetic predisposition has increased in importance over the course of the pandemic. This effect remained significant when we limited ourselves to 4 questionnaires that all have been filled in by the same 7,502 samples to ensure that these findings are not the results of attrition bias (Note S2)

There are several possible social and psychological explanations for the increasing influence of genetics on the reported quality of life over time. One possibility is that, due to lockdown restrictions, people had fewer social contacts, which are known to affect well-being (26). This social isolation could explain a diminished environmental influence on wellbeing relative to the genetic 
component. Alternatively, traumatic events can trigger depressive episodes in people with a genetic predisposition for depression and people who have a strong neurotic personality respond more strongly to stressors $(27,28)$. Since the Life satisfaction-PGS is negatively correlated with the Depression-PGS (Pearson r: $-0.64 p$-value: $\leq 2.22 x^{-308}$ ) and Neuroticism-PGS (Pearson $r:-0.71 p$-value: $\left.\leq 2.22 x^{-308}\right)$, this could potentially explain people's reduced resilience in the presence of the prolonged stress caused by the pandemic. This is also consistent with our finding that people with a high PGS for Depression or Neuroticism report being more tired, an effect that also increased in strength as the pandemic progressed. Either of these factors - social isolation or traumatic impact could explain why people with a lower PGS for life satisfaction had more difficulty dealing with the COVID-19 pandemic.

An alternate possibility is that the arrival of COVID-19 and the accompanying lockdown measures had a very strong impact on the quality of life of the society, such that the contribution of genetics on perceived quality of life was suddenly much smaller. Over time, with a waning impact of this stressor, the effect of genetics became more dominant, reflecting a return to the impact it had prior to the emergence of COVID-19. Unfortunately, we cannot directly test this hypothesis since we have no pre-pandemic measurement on perceived quality of life. However, the Twins Early Development Study on adult twins in Great Britain did show that the first month of lockdown did not result in major changes in the genetic or environmental origins in psychological or attitudinal traits compared

152 to a pre-pandemic timepoint (29). This supports the explanation that the increase in the contribution of genetics that we observe is a consequence of the ongoing pandemic rather than a slow return to a pre-pandemic situation. 


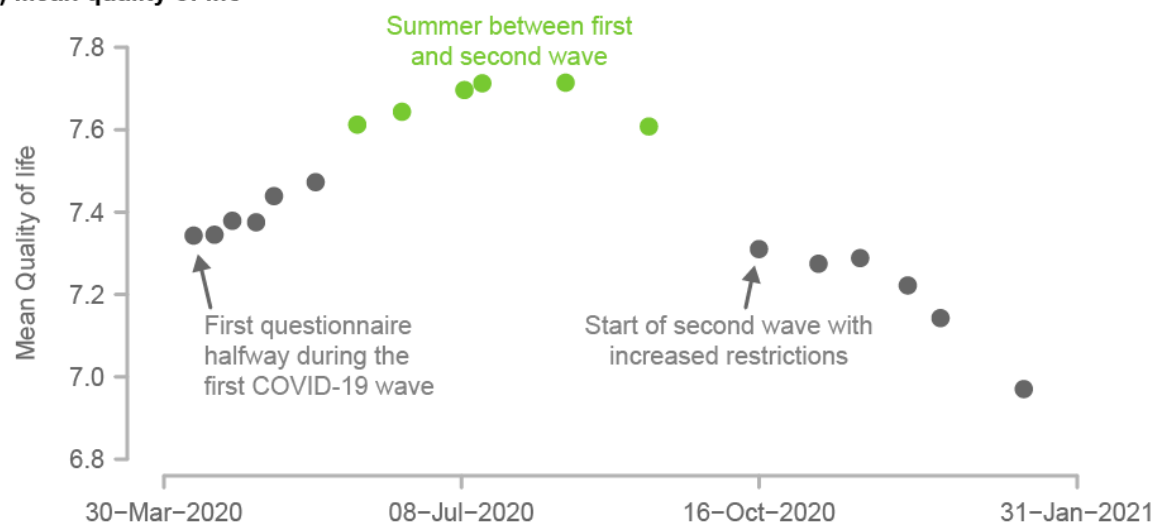

b) Fitted model in 12,522 global screening array samples

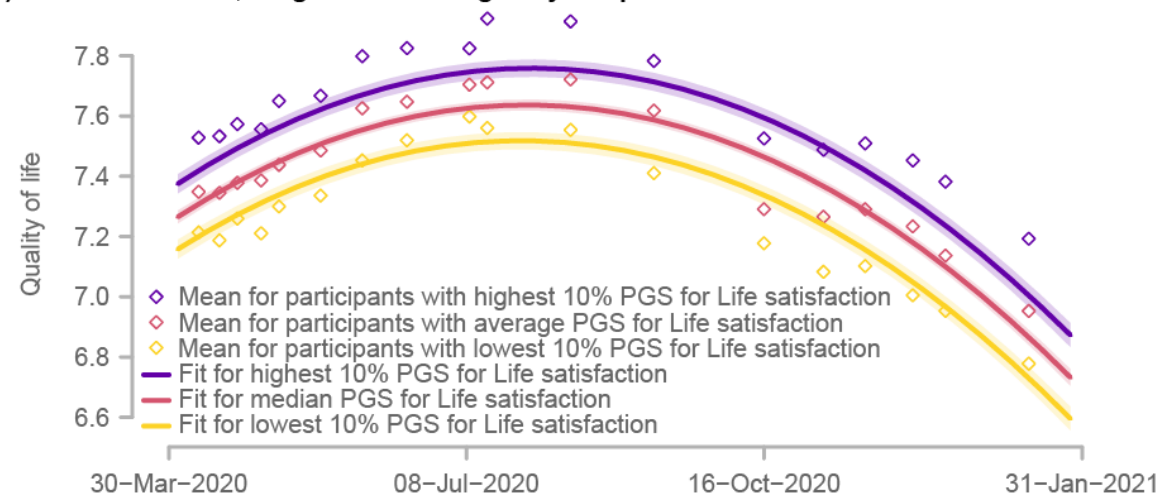

c) Relative contribution of Life satisfaction PGS increases (meta-analysis p-value: $3.1 \times 10^{-3}$ )

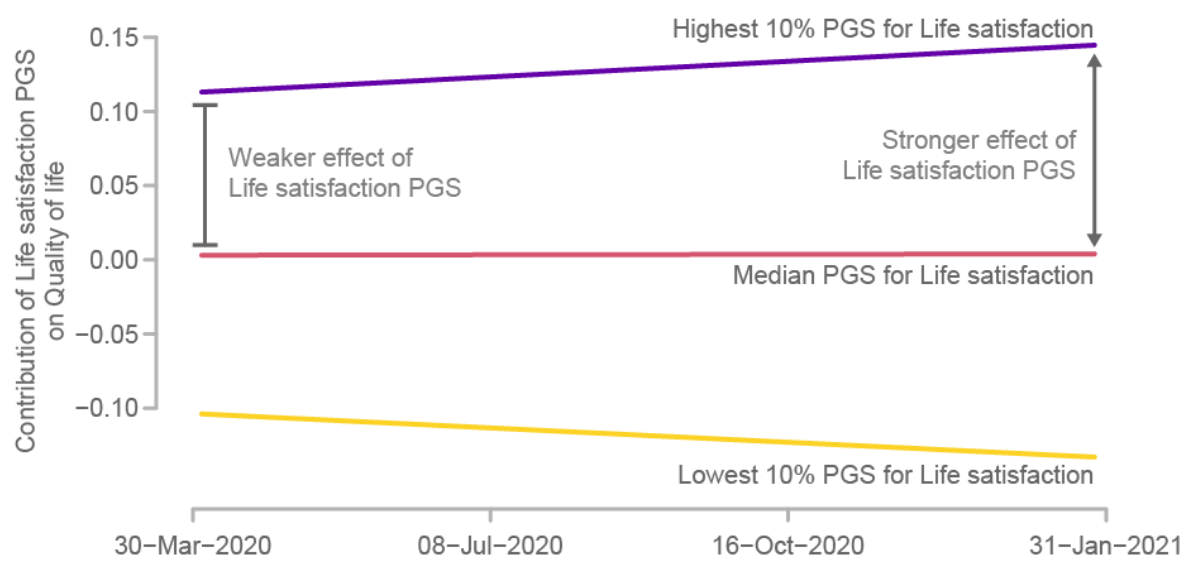

d) Correlation between Life satisfaction PGS and quality of life is higher in later questionnaires

$0.97 \overrightarrow{\text { Explained variance of Life statisfaction PGS }}$ increases in later questionnaires

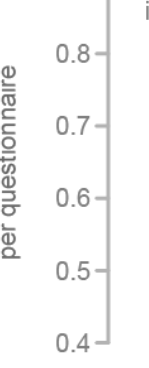

30-Mar-2020

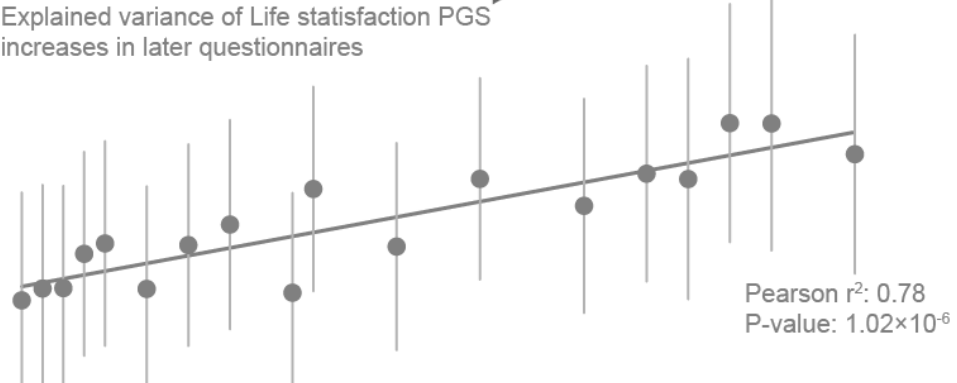

P-value: $1.02 \times 10^{-6}$ 

for Life satisfaction of the samples genotyped on the Global Screening Array (for other samples see Fig. S4). c) Contribution of the Life satisfaction-PGS to perceived quality of life over time. The diverging lines indicate the increased importance of the Life satisfaction PGS to perceived quality of life as time progresses. d) Regression coefficients of the Life satisfaction PGS and perceived quality of life over time. This shows an increase in the explained variance of the PGS during the COVID-19 pandemic.

\section{Host genetic contribution to COVID-19 infections}

A change in the influence of genetics, as seen in PGSs, over time is not restricted to wellbeing outcomes. We also observed a change in the influence of the PGS for COVID-19 susceptibility on infections. As we discuss below, this probably reflects a very different mechanism (a shift in who becomes infected over time), but the presence of a changing effect in a PGS measuring a very different kind of parameter lends support to the idea that such effects are real and need to be considered when applying PGS in other contexts.

As expected, we observed a strong increase in the number of infections among participants over the course of our study (Fig. 4). At the start of our study in March 2020, only 198 infections within our region had been reported by the government, whereas this number had increased to 7,579 in January 2021 (30). While the PGS for COVID-19 susceptibility increased the risk of being infected ( $p$ value: $1.28 \times 10^{-22}$ ), we also observed that the effect of this PGS declined over time ( $p$-value: $5.15 \times 10^{-}$ $\left.{ }^{30}\right)$. One possible explanation for this is testing bias. At the beginning of the pandemic in the Netherlands, testing was almost exclusively reserved for severely ill patients. It was only in June 2020 that anyone with symptoms could get a test (31) and only in the months following that testing was extended to asymptomatic individuals who had been in contact with someone who tested positive for a SARS-CoV-2 infection. We suspect that the same bias exists in the COVID-19 susceptibility GWAS. Some of its signal is likely informative for COVID-19 severity rather than susceptibility, which implies that the performance of this GWAS diminishes once infected people 
182 with few or no symptoms are being widely tested. It could be that the host's genetics for COVID-19

183 susceptibility is slightly different for newly emerging and more infectious SARS-CoV-2 variants, such

184 as B.1.1.7, making the current PGS less informative. 
a) COVID-19 infection incidence curve

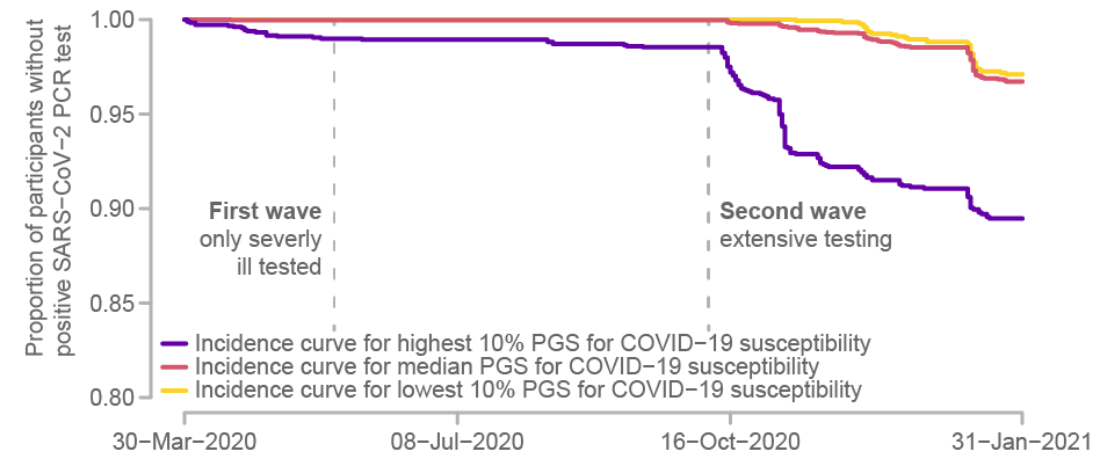

b) Fitted model in 12,541 global screening array samples

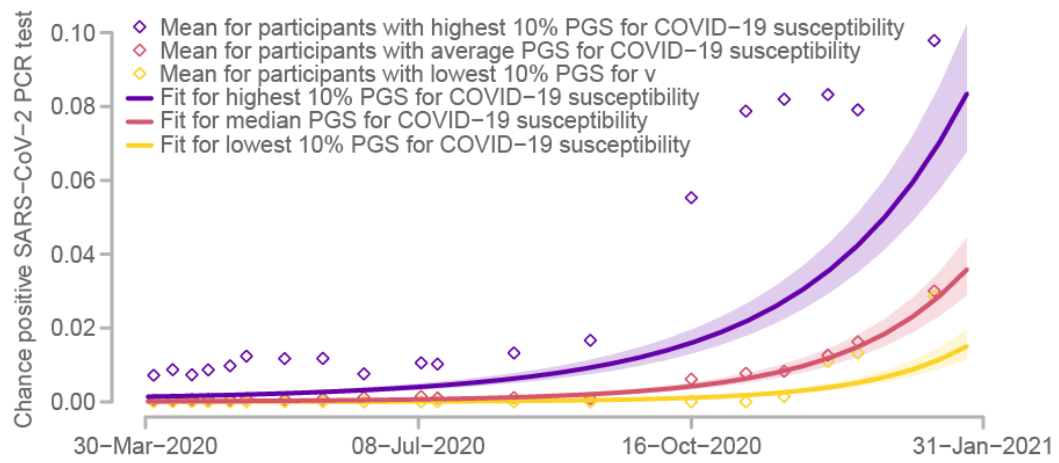

c) Relative contribution of COVID-19 susceptibility PGS increases (meta-analysis p-value: $5.15 \times 10^{-30}$ )

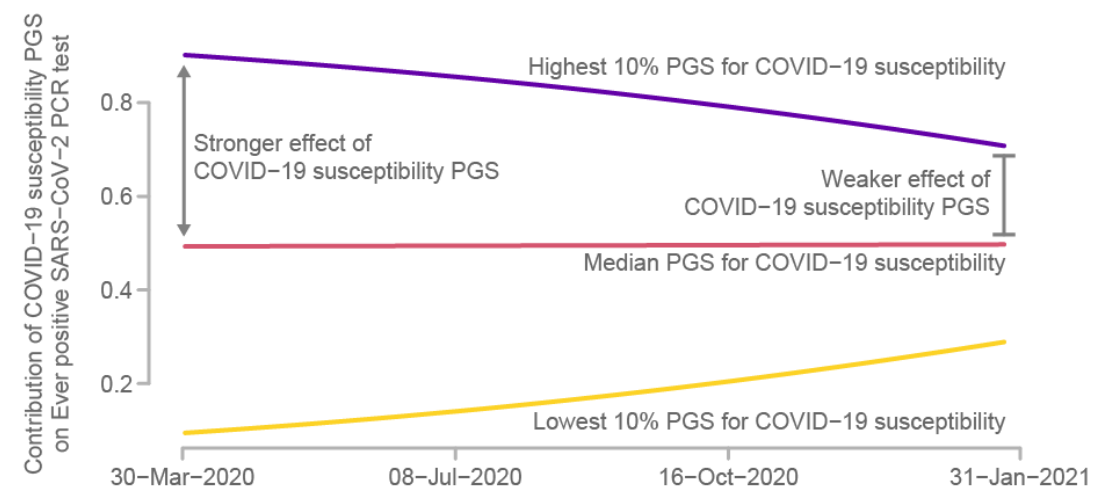

d) Correlation between COVID-19 susceptibility PGS and infections is lower in later questionnaires

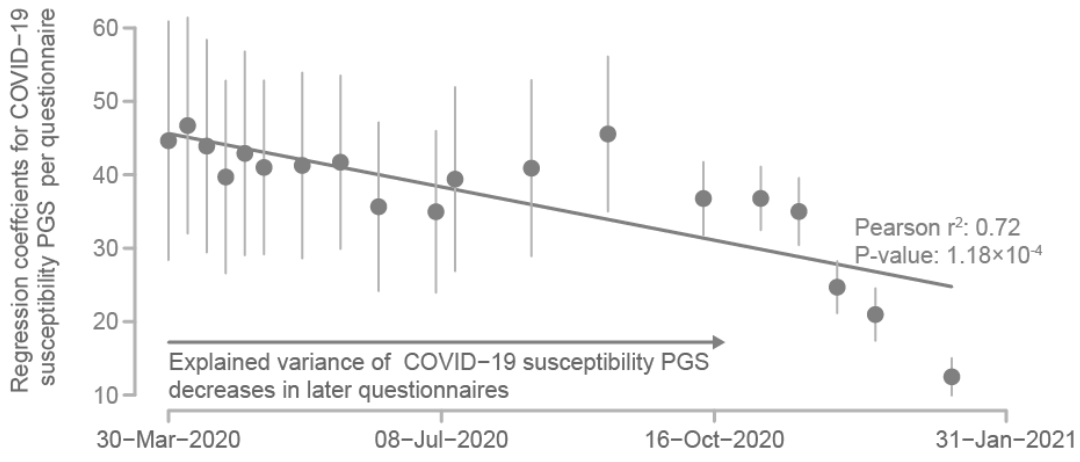


a) Kaplan-Meier curve stratified by genetic risk for COVID-19 infections. b) Fitted logistic longitudinal model for COVID-19 shows increasing infections regardless of genetic risk. c) The contribution of COVID-19 susceptibility to the risk of having had COVID-19 slowly decreased over time. d) Regression coefficients of the COVID-19 susceptibility PGS and ever testing positive for SARS-CoV-2 by PCR test over time. The plot shows a decrease in the variance explained by the PGS during the COVID-19 pandemic.

\section{Discussion}

We have been in the unique position to observe a synchronized and prolonged exposure to a shared continuous stress factor and an increasingly abundant infectious disease. This allowed us to observe longitudinal changes in the relative contribution of nature and nurture on wellbeing and COVID-19 infections. Although the genetic effect on wellbeing became stronger over time, its contribution remains relatively small. Our findings demonstrate that it is not only the presence or absence of environmental stimuli that can modulate the effect of genetic variants, the duration of a stimulus in conjunction with a genetic background can also modulate the outcome. Accounting for this by the use of longitudinal biobanks, would help improve the power of GWASs to detect associated variants (32), enable more accurate risk predictions using PGSs and allow more accurate patient stratification (33), and provide insights into the complex interplay of genetic predisposition and environment on disease and traits (34).

\section{Methods}

\section{Cohort}

207 We selected study participants from the Lifelines COVID-19 cohort (9), for which adult participants were recruited from the Lifelines population cohort (35). Lifelines is a prospective multigenerational population cohort following 167,000 individuals in the three northern provinces of the Netherlands

210 (Drenthe, Friesland, Groningen) since 2006, and collects detailed information and biological samples from its participants (Fig. 1). The repeated questionnaires sent out to the Lifelines COVID-19 cohort include items about sociodemographic parameters, chronic diseases, COVID-19 infection, general 
health and symptoms, medication use, mental health, well-being, social life and lifestyle. At least once a month, participants were invited to respond to these questionnaires. In total, 19 questionnaires were sent out between March 30, 2020 and January 5, 2021. On average, 39,066 participants responded to each questionnaire (Table S1). There are 27,537 participants that passed quality control and for whom genotype data was available. Of these 17,831 could be used in the longitudinal analyses (Table S1).

\section{Questionnaire quality control}

We started with 27,536 participants for whom we have genetic data and who had completed at least one questionnaire. To enable quality control, we first selected questions that were answered by at least $95 \%$ of the participants of that questionnaire. This resulted in at least 98 questions per questionnaire that were answered by nearly all participants. Subsequently, we calculated the per participant missing rate for each questionnaire for these questions. For each participant, we excluded the questionnaires with more than $5 \%$ "missing-ness". Next, to include participants with long-term follow-up, we selected participants who had completed at least one questionnaire in the first half of our study and at least one questionnaire in the second half. Using these criteria, we ultimately included 17,831 participants who had completed an average of 13 out of the 19 questionnaires (Fig. S1).

To ensure that our questionnaires were filled in reliably, we performed a principal component analysis (PCA) for each of the 19 questionnaires to detect spurious signals. The answers to questions with a maximum of $5 \%$ missingness were normalized to have a mean of 0 and a standard deviation of 1 . At this point, we still had some missing values in our data, which prevented us from performing a simple PCA. There are many ways to resolve this, but for the purpose of quality control, we decided to simply fill missing answers with the mean answer for that question. Subsequently, we normalized each sample to have a mean of 0 and standard deviation of 1 . Finally, we performed a 
larger than 4, suggesting the absence of respondents who filled out the questionnaires with erroneous answers. As such, we did not need to remove samples from the dataset.

We assessed the effects of quality control and sample exclusions on the PGSs by comparing the participants who were included in this study to those who were invited to take part in the Lifelines COVID-19 questionnaires but were not included. These either did not respond or did not pass quality control. Welsh's t-tests are used to assess whether differences were significant. For 7 traits in the samples genotyped using the Global Screening Array (GSA), and for 3 traits in the samples genotyped using the HumanCytoSNP-12 array, the PGSs of the included samples in longitudinal analyses are different compared to the samples that were invited (Fig. S9). The figure also demonstrate that sample selection based on quality control has been favourable for controlling false positives caused by loss to follow-up.

\section{Genetic data and polygenic scores}

After sample selection and quality control, we had 27,537 participants who regularly completed questionnaires and for whom we have genetic data. These individuals were a priori filtered to only include samples of European ancestry according to principal component analysis. Of these 27,537 samples, 19,703 were genotyped using the GSA and 7,834 using the HumanCytoSNP-12 array. Both arrays were imputed on the Sanger imputation server using the Human Reference Consortium reference panel (37).

We calculated PGSs by applying PGS-CS (38) to our defined set of traits (Table S3). For each of the traits, we downloaded the complete summary statistics from the indicated source. To comply with the PGS-CS input format, we added reference SNP identifiers (RSIDs) to the GWAS summary statistics, when these were not initially present, by matching genomic locations for each of the variants to those from dbSNP (39). For the genotype data generated with the HumanCytoSNP array, RSIDs were matched to the genotype data when the genomic location and both the alleles matched variants from dbSNP (build 152). This was not necessary for the genotype data generated with the 
GSA. Thereafter, we excluded SNPs with ambiguous alleles. We also removed SNPs with a minor allele frequency below 0.01 , an imputation score below 0.3 , or a missing call rate greater than 0.25 .

PGS-CS accounts for inaccuracies in effect sizes and linkage disequilibrium (LD) patterns using a reference panel and through shrinkage of effect-size estimates. It does not require pruning or thresholding of variants. PGS-CS was run on each autosome separately using the processed PLINK datasets and the complete GWAS summary statistics. We used the European reference LD panel provided by the PGS-CS authors and the default for the other parameter options. PLINK 2.0 was used to sum variant dosages from the PLINK datasets, weighted by the posterior effect sizes calculated by PGS-CS. Finally, we summed the PGSs that were calculated separately for each of the autosomes and scaled the outcomes to have a mean of 0 and a standard deviation of 1.

\section{Outcome items}

We recoded questionnaire items to either an ordinal or dichotomous data type when this was not already the case (Table S4). In particular, we made sure that the ordering of the ordinal and dichotomous answers corresponded to the directionality implied by the given label or question. We additionally were required to exclude answers that did not fit on the ordinal scale, like answers indicating that the question was not applicable to the individual. After recoding, we removed all the questions where the most frequent answer was given by more than $99 \%$ of the participants.

In addition to single questionnaire items, we derived a set of additional outcome items. Current depressive episode was calculated using the decision tree from the standardized "Mini-International Neuropsychiatric Interview (M.I.N.I.)" version 5.0.0. questionnaire manual (36). We excluded the question "Did you feel tired or without energy almost every day?" because this question was not available in all of the questionnaires. We also excluded the timepoints for which the question "Did you repeatedly consider hurting yourself, feel suicidal, or wish that you were dead?" was not available. We determined whether participants were ever tested positive for a SARS-CoV-2 infection 
with a PCR test. For this, we used a series of questions asking if a PCR test was performed and if the test result was positive or negative. The resulting "ever positive SARS-CoV-2 PCR test" variable was defined per participant and set as True for all following questionnaires, starting from the first selfreported positive SARS-CoV-2 PCR test.

BMI was calculated using the most recent self-reported body weight in the questionnaires and the height that had been measured during the most recent physical visit. Weight values below $20 \mathrm{~kg}$ and above $220 \mathrm{~kg}$ were removed. Measures with an absolute difference of more than $20 \mathrm{~kg}$ compared to the last previous questionnaire were also removed. The first measure was compared to the second and third measure and was removed if the absolute difference to the second measure was more than $20 \mathrm{~kg}$ and that to the third measure was more than $30 \mathrm{~kg}$. If only two questionnaires were completed, both points were removed if the absolute difference was more than $20 \mathrm{~kg}$.

\section{Covariates}

We used the participant's sex as registered in the Personal Records Database (42). Their age, derived using date of birth and date of questionnaire completion, was available for every questionnaire. We used the age at the time of the most recently completed questionnaire. We also assessed if participants live alone or not. This was defined as having zero household members, which we determined using the most recent self-reported number of household members. We also determined whether participants have children living at home using the question on whether participants have children and the most recent number of household members reported below 18 years of age. Chronic illness was extracted from the most recent self-reported chronic disease item. Time was defined as days since March 30, 2020.

\section{Baseline associations}

To identify correlations between responses to questionnaire items and PGSs, we fitted models between all PGSs and both the questionnaire items and derived items. First, we filtered the questions for which the answers were not directly influenced by the participant. For example, we 
removed questions about choices made by their employer. After manual selection, we removed all the questions that were answered by less than $50 \%$ of the participants of the questionnaire in which that particular question was asked.

For each question, we selected the appropriate regression model. We chose a normal linear regression model for normally distributed outcomes, a logistic model for binomial data and an ordinal logistic regression model for ordered categorical data.

The models were fitted using the Python 'statsmodels' package. The quantitative questions were fitted using the OLS class, the binominal questions were fitted using the Logit class and the ordinal questions where fit by the 'OrderedModel' class. For the 'OrderedModel', we set the 'distr' option to logit, set the maximal number of iterations to 10,000 and set the optimizer to the Broyden-FletcherGoldfarb-Shanno (BFGS) method. The models were fitted for each PGS and each question individually while adjusting for sex, age, age ${ }^{2}$, chronic illness, living alone and children living at home. The models were fitted separately for each genotype array and the regression coefficients and $p$ values were combined with the inverse-variance weighting method. Afterwards, the p-values were translated to z-scores and filtered on significance using a Bonferroni-corrected $\alpha$ of 0.05 .

For all PGS-question pairs for which we identified a significant baseline association, we tested if this effect was stable over time. There are 237 PGS-question pairs for questions that did have longitudinal data. For 46 PGS-question pairs we were able to fit mixed-effect models with a random intercept, time and time ${ }^{2}$ per participant (except for the model for "ever positive SARS-CoV-2 PCR test" in which we only used a fixed intercept). To investigate differences in changes over time, we included interaction with time for all included variables:

$$
y=\beta_{0}+\beta_{1 p} \times P G S+\beta_{2} \times P G S \times \text { time }+\beta_{3} \times \text { time }+\beta_{4} \times \text { time } e^{2}+\beta_{5 c} \times \text { confounders }
$$

$$
+\beta_{6 c} \times \text { confounders } \times \text { time }+u_{s}+\varepsilon
$$


Time was denoted as days since March 30, 2020. We included time and time ${ }^{2}$ to model the nonlinear changes over time and adjusted for sex, age (mean-centred), age ${ }^{2}$, chronic illness (0/1), living alone (0/1) and children living at home (0/1).

We used the Ime function from the nlme package for questions with a quantitative answer. Here, we used the optim optimizer (47). For "ever positive SARS-CoV-2 PCR test", we used the R GLM function with binominal logit link function (48). The other questions, which have binary outcomes, were fitted using the glmer function with the binominal logit link function and $\mathrm{nAGQ}=0$ parameter from the Ime4 package (49).

Since our cohort was genotyped on two different genotyping arrays, we fitted the model above for each array separately. We used inverse-variance weighting to combine the estimates and standard errors for each term in the model (50). These where then used to calculate the combined z-score and $p$-value that we used to determine the significance of each term.

\section{Sensitivity analysis}

We performed a sensitivity analysis using separate linear and logistic models for each questionnaire item on each individual timepoint. The resulting regression coefficients of the PGSs for each time point were subsequently correlated with time to analyse if the effect of the PGSs on the different (derived) outcomes changed over time. For each timepoint and each item, we used linear, logistic, or ordinal regression models which were also used by calculating the baseline associations, including recoding criteria and parameters for the models and with adjustment for sex, age, age ${ }^{2}$, chronic illness, living alone and children living at home. The regression coefficients of the PGSs were extracted from the models and grouped per question. These models were fitted separately for each genotype array and the regression coefficients were combined with the inverse-variance weighting method. Subsequently, for each PGS and each question, we calculated the Pearson correlation between the PGS regression coefficients and time (in days) since March 30, 2021 to analyse if the effect of the PGS on the answer to the question changed over time. 
We collected a number of publicly available datasets that we hypothesized might be able to explain part of the variation in the perceived quality of life over the course of the pandemic. We collected three variables that convey the state of the pandemic in the Netherlands: the confirmed COVID-19 cases per day published by the Dutch National Institute for Public Health and the Environment in the Netherlands, we downloaded the 'Stringency Index' from the Oxford COVID-19 Government Response Tracker (44). Additionally, we retrieved the relative change in work- and recreationalrelated mobility from the Google COVID-19 Community Mobility Reports (45). Finally, we downloaded a dataset on the weather per day from The Royal Netherlands Meteorological Institute for a central Northern Netherlands weather station (Eelde, Drenthe) (46).

A 7-day moving average was calculated for the confirmed COVID-19 cases, the relative change in both work and recreational mobility, the hours of sunshine per day and the average temperature over 24 hours (in degrees Celsius). These variables are visualized together with the ICU occupancy by COVID-19 patients and the Stringency Index (Fig. S7). Together with the publicly available variables, this figure presents the mean perceived quality of life per questionnaire over the average response date for that questionnaire.

For each of the visualized variables, we extracted the values that coincided with the average response dates for the questionnaires. Thereafter, the Pearson correlation was calculated between each of these variables and the mean perceived quality of life (Fig. S8, Table S9).

Results were frequently shared with participants and the general public through interactive infographics on the Corona Barometer website (https://coronabarometer.nl/). The individual-level data that support the findings were obtained from the Lifelines biobank under project application 
number ov20_0554. Data is made available upon reasonable request submitted to the LifeLines

Research office (research@lifelines.nl, https://www.lifelines.nl/researcher/how-to-apply/apply-

here). The data are not publicly available because they contain information that could compromise

research participant privacy and consent.

\section{Code availability}

All code that is central to this paper is made available via GitHub

(https://github.com/molgenis/covid19 prs time). Other analyses of genotype data and publicly

available reference data and is performed using standard bioinformatics practices, for which the

code is made available upon request.

\section{References}

1. L. Colodro-Conde, B. Couvy-Duchesne, G. Zhu, W. L. Coventry, E. M. Byrne, S. Gordon, M. J. Wright, G. W. Montgomery, P. a. F. Madden, Major Depressive Disorder Working Group of the Psychiatric Genomics Consortium, S. Ripke, L. J. Eaves, A. C. Heath, N. R. Wray, S. E. Medland, N. G. Martin, A direct test of the diathesis-stress model for depression. Mol. Psychiatry. 23, 1590-1596 (2018).

2. Generation Scotland, Major Depressive Disorder Working Group of the Psychiatric Genomics Consortium, A. Arnau-Soler, M. J. Adams, T.-K. Clarke, D. J. Maclntyre, K. Milburn, L. Navrady, C. Hayward, A. McIntosh, P. A. Thomson, A validation of the diathesis-stress model for depression in Generation Scotland. Transl. Psychiatry. 9, 25 (2019).

3. C. Chasiropoulou, N. Siouti, T. Mougiakos, S. Dimitrakopoulos, The diathesis-stress model in the emergence of major psychiatric disorders during military service. Psychiatr. Psychiatr. 30, 291298 (2019).

4. J. R. I. Coleman, W. J. Peyrot, K. L. Purves, K. A. S. Davis, C. Rayner, S. W. Choi, C. Hübel, H. A. Gaspar, C. Kan, S. Van der Auwera, M. J. Adams, D. M. Lyall, K. W. Choi, on the behalf of Major Depressive Disorder Working Group of the Psychiatric Genomics Consortium, E. C. Dunn, E. Vassos, A. Danese, B. Maughan, H. J. Grabe, C. M. Lewis, P. F. O'Reilly, A. M. McIntosh, D. J. Smith, N. R. Wray, M. Hotopf, T. C. Eley, G. Breen, Genome-wide gene-environment analyses of major depressive disorder and reported lifetime traumatic experiences in UK Biobank. Mol. Psychiatry. 25, 1430-1446 (2020).

5. S. K. Brooks, R. K. Webster, L. E. Smith, L. Woodland, S. Wessely, N. Greenberg, G. J. Rubin, The psychological impact of quarantine and how to reduce it: rapid review of the evidence. Lancet Lond. Engl. 395, 912-920 (2020).

6. J. Xiong, O. Lipsitz, F. Nasri, L. M. W. Lui, H. Gill, L. Phan, D. Chen-Li, M. lacobucci, R. Ho, A. Majeed, R. S. McIntyre, Impact of COVID-19 pandemic on mental health in the general population: A systematic review. J. Affect. Disord. 277, 55-64 (2020).

7. J. Qiu, B. Shen, M. Zhao, Z. Wang, B. Xie, Y. Xu, A nationwide survey of psychological distress among Chinese people in the COVID-19 epidemic: implications and policy recommendations. Gen. Psychiatry. 33, e100213 (2020). 
8. S. Sun, S. B. Goldberg, D. Lin, S. Qiao, D. Operario, Psychiatric symptoms, risk, and protective factors among university students in quarantine during the COVID-19 pandemic in China. Glob. Health. 17, 15 (2021).

9. K. Mc Intyre, P. Lanting, P. Deelen, H. H. Wiersma, J. M. Vonk, A. P. S. Ori, S. A. Jankipersadsing, R. Warmerdam, I. van Blokland, F. Boulogne, M. X. L. Dijkema, J. C. Herkert, A. Claringbould, O. Bakker, E. A. Lopera Maya, U. Bültmann, A. Zhernakova, S. A. Reijneveld, E. Zijlstra, M. A. Swertz, S. Brouwer, R. van Ooijen, V. Angelini, L. H. Dekker, A. Sijtsma, S. A. Scherjon, C. Wijmenga, J. A. M. Dekens, J. Mierau, H. M. Boezen, L. Franke, Lifelines COVID-19 cohort: investigating COVID-19 infection and its health and societal impacts in a Dutch populationbased cohort. BMJ Open. 11, e044474 (2021).

10. L. Yengo, J. Sidorenko, K. E. Kemper, Z. Zheng, A. R. Wood, M. N. Weedon, T. M. Frayling, J. Hirschhorn, J. Yang, P. M. Visscher, GIANT Consortium, Meta-analysis of genome-wide association studies for height and body mass index in $~ 700000$ individuals of European ancestry. Hum. Mol. Genet. 27, 3641-3649 (2018).

11. The COVID-19 Host Genetics Initiative, A. Ganna, "Mapping the human genetic architecture of COVID-19 by worldwide meta-analysis" (preprint, Genetic and Genomic Medicine, 2021), , doi:10.1101/2021.03.10.21252820.

12. J. J. Lee, R. Wedow, A. Okbay, E. Kong, O. Maghzian, M. Zacher, T. A. Nguyen-Viet, P. Bowers, J. Sidorenko, R. Karlsson Linnér, M. A. Fontana, T. Kundu, C. Lee, H. Li, R. Li, R. Royer, P. N. Timshel, R. K. Walters, E. A. Willoughby, L. Yengo, 23andMe Research Team, COGENT (Cognitive Genomics Consortium), Social Science Genetic Association Consortium, M. Alver, Y. Bao, D. W. Clark, F. R. Day, N. A. Furlotte, P. K. Joshi, K. E. Kemper, A. Kleinman, C. Langenberg, R. Mägi, J. W. Trampush, S. S. Verma, Y. Wu, M. Lam, J. H. Zhao, Z. Zheng, J. D. Boardman, H. Campbell, J. Freese, K. M. Harris, C. Hayward, P. Herd, M. Kumari, T. Lencz, J. Luan, A. K. Malhotra, A. Metspalu, L. Milani, K. K. Ong, J. R. B. Perry, D. J. Porteous, M. D. Ritchie, M. C. Smart, B. H. Smith, J. Y. Tung, N. J. Wareham, J. F. Wilson, J. P. Beauchamp, D. C. Conley, T. Esko, S. F. Lehrer, P. K. E. Magnusson, S. Oskarsson, T. H. Pers, M. R. Robinson, K. Thom, C. Watson, C. F. Chabris, M. N. Meyer, D. I. Laibson, J. Yang, M. Johannesson, P. D. Koellinger, P. Turley, P. M. Visscher, D. J. Benjamin, D. Cesarini, Gene discovery and polygenic prediction from a genome-wide association study of educational attainment in 1.1 million individuals. Nat. Genet. 50, 1112-1121 (2018).

13. B. M. L. Baselmans, R. Jansen, H. F. Ip, J. van Dongen, A. Abdellaoui, M. P. van de Weijer, Y. Bao, M. Smart, M. Kumari, G. Willemsen, J.-J. Hottenga, BIOS consortium, Social Science Genetic Association Consortium, D. I. Boomsma, E. J. C. de Geus, M. G. Nivard, M. Bartels, Multivariate genome-wide analyses of the well-being spectrum. Nat. Genet. 51, 445-451 (2019).

14. M. Nagel, P. R. Jansen, S. Stringer, K. Watanabe, C. A. de Leeuw, J. Bryois, J. E. Savage, A. R. Hammerschlag, N. G. Skene, A. B. Muñoz-Manchado, 23andMe Research Team, T. White, H. Tiemeier, S. Linnarsson, J. Hjerling-Leffler, T. J. C. Polderman, P. F. Sullivan, S. van der Sluis, D. Posthuma, Meta-analysis of genome-wide association studies for neuroticism in 449,484 individuals identifies novel genetic loci and pathways. Nat. Genet. 50, 920-927 (2018).

15. W. D. Hill, A. Weiss, D. C. Liewald, G. Davies, D. J. Porteous, C. Hayward, A. M. McIntosh, C. R. Gale, I. J. Deary, Genetic contributions to two special factors of neuroticism are associated with affluence, higher intelligence, better health, and longer life. Mol. Psychiatry. 25, 3034-3052 (2020).

16. Y. C. Klimentidis, D. A. Raichlen, J. Bea, D. O. Garcia, N. E. Wineinger, L. J. Mandarino, G. E. Alexander, Z. Chen, S. B. Going, Genome-wide association study of habitual physical activity in over 377,000 UK Biobank participants identifies multiple variants including CADM2 and APOE. Int. J. Obes. 2005. 42, 1161-1176 (2018).

17. R. Karlsson Linnér, P. Biroli, E. Kong, S. F. W. Meddens, R. Wedow, M. A. Fontana, M. Lebreton, S. P. Tino, A. Abdellaoui, A. R. Hammerschlag, M. G. Nivard, A. Okbay, C. A. Rietveld, P. N. 
Timshel, M. Trzaskowski, R. de Vlaming, C. L. Zünd, Y. Bao, L. Buzdugan, A. H. Caplin, C.-Y. Chen, P. Eibich, P. Fontanillas, J. R. Gonzalez, P. K. Joshi, V. Karhunen, A. Kleinman, R. Z. Levin, C. M. Lill, G. A. Meddens, G. Muntané, S. Sanchez-Roige, F. J. van Rooij, E. Taskesen, Y. Wu, F. Zhang, 23and Me Research Team, eQTLgen Consortium, International Cannabis Consortium, Social Science Genetic Association Consortium, A. Auton, J. D. Boardman, D. W. Clark, A. Conlin, C. C. Dolan, U. Fischbacher, P. J. F. Groenen, K. M. Harris, G. Hasler, A. Hofman, M. A. Ikram, S. Jain, R. Karlsson, R. C. Kessler, M. Kooyman, J. MacKillop, M. Männikkö, C. Morcillo-Suarez, M. B. McQueen, K. M. Schmidt, M. C. Smart, M. Sutter, A. R. Thurik, A. G. Uitterlinden, J. White, H. de Wit, J. Yang, L. Bertram, D. I. Boomsma, T. Esko, E. Fehr, D. A. Hinds, M. Johannesson, M. Kumari, D. Laibson, P. K. E. Magnusson, M. N. Meyer, A. Navarro, A. A. Palmer, T. H. Pers, D. Posthuma, D. Schunk, M. B. Stein, R. Svento, H. Tiemeier, P. R. H. J. Timmers, P. Turley, R. J. Ursano, G. G. Wagner, J. F. Wilson, J. Gratten, J. J. Lee, D. Cesarini, D. J. Benjamin, P. D. Koellinger, J. P. Beauchamp, Genome-wide association analyses of risk tolerance and risky behaviors in over 1 million individuals identify hundreds of loci and shared genetic influences. Nat. Genet. 51, 245-257 (2019).

18. M. Liu, Y. Jiang, R. Wedow, Y. Li, D. M. Brazel, F. Chen, G. Datta, J. Davila-Velderrain, D. McGuire, C. Tian, X. Zhan, 23andMe Research Team, HUNT All-In Psychiatry, H. Choquet, A. R. Docherty, J. D. Faul, J. R. Foerster, L. G. Fritsche, M. E. Gabrielsen, S. D. Gordon, J. Haessler, J.-J. Hottenga, H. Huang, S.-K. Jang, P. R. Jansen, Y. Ling, R. Mägi, N. Matoba, G. McMahon, A. Mulas, V. Orrù, T. Palviainen, A. Pandit, G. W. Reginsson, A. H. Skogholt, J. A. Smith, A. E. Taylor, C. Turman, G. Willemsen, H. Young, K. A. Young, G. J. M. Zajac, W. Zhao, W. Zhou, G. Bjornsdottir, J. D. Boardman, M. Boehnke, D. I. Boomsma, C. Chen, F. Cucca, G. E. Davies, C. B. Eaton, M. A. Ehringer, T. Esko, E. Fiorillo, N. A. Gillespie, D. F. Gudbjartsson, T. Haller, K. M. Harris, A. C. Heath, J. K. Hewitt, I. B. Hickie, J. E. Hokanson, C. J. Hopfer, D. J. Hunter, W. G. Iacono, E. O. Johnson, Y. Kamatani, S. L. R. Kardia, M. C. Keller, M. Kellis, C. Kooperberg, P. Kraft, K. S. Krauter, M. Laakso, P. A. Lind, A. Loukola, S. M. Lutz, P. A. F. Madden, N. G. Martin, M. McGue, M. B. McQueen, S. E. Medland, A. Metspalu, K. L. Mohlke, J. B. Nielsen, Y. Okada, U. Peters, T. J. C. Polderman, D. Posthuma, A. P. Reiner, J. P. Rice, E. Rimm, R. J. Rose, V. Runarsdottir, M. C. Stallings, A. Stančáková, H. Stefansson, K. K. Thai, H. A. Tindle, T. Tyrfingsson, T. L. Wall, D. R. Weir, C. Weisner, J. B. Whitfield, B. S. Winsvold, J. Yin, L. Zuccolo, L. J. Bierut, K. Hveem, J. J. Lee, M. R. Munafò, N. L. Saccone, C. J. Willer, M. C. Cornelis, S. P. David, D. A. Hinds, E. Jorgenson, J. Kaprio, J. A. Stitzel, K. Stefansson, T. E. Thorgeirsson, G. Abecasis, D. J. Liu, S. Vrieze, Association studies of up to 1.2 million individuals yield new insights into the genetic etiology of tobacco and alcohol use. Nat. Genet. 51, 237-244 (2019).

19. Schizophrenia Working Group of the Psychiatric Genomics Consortium, Biological insights from 108 schizophrenia-associated genetic loci. Nature. 511, 421-427 (2014).

20. International Obsessive Compulsive Disorder Foundation Genetics Collaborative (IOCDF-GC) and OCD Collaborative Genetics Association Studies (OCGAS), Revealing the complex genetic architecture of obsessive-compulsive disorder using meta-analysis. Mol. Psychiatry. 23, 11811188 (2018).

21. D. M. Howard, M. J. Adams, M. Shirali, T.-K. Clarke, R. E. Marioni, G. Davies, J. R. I. Coleman, C. Alloza, X. Shen, M. C. Barbu, E. M. Wigmore, J. Gibson, 23andMe Research Team, S. P. Hagenaars, C. M. Lewis, J. Ward, D. J. Smith, P. F. Sullivan, C. S. Haley, G. Breen, I. J. Deary, A. M. McIntosh, Genome-wide association study of depression phenotypes in UK Biobank identifies variants in excitatory synaptic pathways. Nat. Commun. 9, 1470 (2018).

22. N. Matoba, D. Liang, H. Sun, N. Aygün, J. C. McAfee, J. E. Davis, L. M. Raffield, H. Qian, J. Piven, Y. Li, S. Kosuri, H. Won, J. L. Stein, Common genetic risk variants identified in the SPARK cohort support DDHD2 as a candidate risk gene for autism. Transl. Psychiatry. 10, 265 (2020).

23. P. T. Costa, R. R. McCrae, Influence of extraversion and neuroticism on subjective well-being: Happy and unhappy people. J. Pers. Soc. Psychol. 38, 668-678 (1980). 
24. D. Watson, J. W. Pennebaker, Health complaints, stress, and distress: Exploring the central role of negative affectivity. Psychol. Rev. 96, 234-254 (1989).

25. A. Okbay, B. M. L. Baselmans, J.-E. De Neve, P. Turley, M. G. Nivard, M. A. Fontana, S. F. W. Meddens, R. K. Linnér, C. A. Rietveld, J. Derringer, J. Gratten, J. J. Lee, J. Z. Liu, R. de Vlaming, T. S. Ahluwalia, J. Buchwald, A. Cavadino, A. C. Frazier-Wood, N. A. Furlotte, V. Garfield, M. H. Geisel, J. R. Gonzalez, S. Haitjema, R. Karlsson, S. W. van der Laan, K.-H. Ladwig, J. Lahti, S. J. van der Lee, P. A. Lind, T. Liu, L. Matteson, E. Mihailov, M. B. Miller, C. C. Minica, I. M. Nolte, D. Mook-Kanamori, P. J. van der Most, C. Oldmeadow, Y. Qian, O. Raitakari, R. Rawal, A. Realo, R. Rueedi, B. Schmidt, A. V. Smith, E. Stergiakouli, T. Tanaka, K. Taylor, G. Thorleifsson, J. Wedenoja, J. Wellmann, H.-J. Westra, S. M. Willems, W. Zhao, N. Amin, A. Bakshi, S. Bergmann, G. Bjornsdottir, P. A. Boyle, S. Cherney, S. R. Cox, G. Davies, O. S. P. Davis, J. Ding, N. Direk, P. Eibich, R. T. Emeny, G. Fatemifar, J. D. Faul, L. Ferrucci, A. J. Forstner, C. Gieger, R. Gupta, T. B. Harris, J. M. Harris, E. G. Holliday, J.-J. Hottenga, P. L. De Jager, M. A. Kaakinen, E. Kajantie, V. Karhunen, I. Kolcic, M. Kumari, L. J. Launer, L. Franke, R. Li-Gao, D. C. Liewald, M. Koini, A. Loukola, P. Marques-Vidal, G. W. Montgomery, M. A. Mosing, L. Paternoster, A. Pattie, K. E. Petrovic, L. Pulkki-Råback, L. Quaye, K. Räikkönen, I. Rudan, R. J. Scott, J. A. Smith, A. R. Sutin, M. Trzaskowski, A. E. Vinkhuyzen, L. Yu, D. Zabaneh, J. R. Attia, D. A. Bennett, K. Berger, L. Bertram, D. I. Boomsma, H. Snieder, S.-C. Chang, F. Cucca, I. J. Deary, C. M. van Duijn, J. G. Eriksson, U. Bültmann, E. J. C. de Geus, P. J. F. Groenen, V. Gudnason, T. Hansen, C. A. Hartman, C. M. A. Haworth, C. Hayward, A. C. Heath, D. A. Hinds, E. Hyppönen, W. G. lacono, M.-R. Järvelin, K.-H. Jöckel, J. Kaprio, S. L. R. Kardia, L. Keltikangas-Järvinen, P. Kraft, L. D. Kubzansky, T. Lehtimäki, P. K. E. Magnusson, N. G. Martin, M. McGue, A. Metspalu, M. Mills, R. de Mutsert, A. J. Oldehinkel, G. Pasterkamp, N. L. Pedersen, R. Plomin, O. Polasek, C. Power, S. S. Rich, F. R. Rosendaal, H. M. den Ruijter, D. Schlessinger, H. Schmidt, R. Svento, R. Schmidt, B. Z. Alizadeh, T. I. A. Sørensen, T. D. Spector, J. M. Starr, K. Stefansson, A. Steptoe, A. Terracciano, U. Thorsteinsdottir, A. R. Thurik, N. J. Timpson, H. Tiemeier, A. G. Uitterlinden, P. Vollenweider, G. G. Wagner, D. R. Weir, J. Yang, D. C. Conley, G. D. Smith, A. Hofman, M. Johannesson, D. I. Laibson, S. E. Medland, M. N. Meyer, J. K. Pickrell, T. Esko, R. F. Krueger, J. P. Beauchamp, P. D. Koellinger, D. J. Benjamin, M. Bartels, D. Cesarini, Genetic variants associated with subjective well-being, depressive symptoms, and neuroticism identified through genomewide analyses. Nat. Genet. 48, 624-633 (2016).

26. D. Umberson, J. K. Montez, Social Relationships and Health: A Flashpoint for Health Policy. J. Health Soc. Behav. 51, S54-S66 (2010).

27. Y. Xin, J. Wu, Z. Yao, Q. Guan, A. Aleman, Y. Luo, The relationship between personality and the response to acute psychological stress. Sci. Rep. 7, 16906 (2017).

28. G. W. Brown, T. O. Harris, Depression and the serotonin transporter 5-HTTLPR polymorphism: A review and a hypothesis concerning gene-environment interaction. J. Affect. Disord. 111, 112 (2008).

29. K. Rimfeld, M. Malanchini, A. G. Allegrini, A. E. Packer, A. McMillan, R. Ogden, L. Webster, N. G. Shakeshaft, K. L. Schofield, J.-B. Pingault, A. Stringaris, S. von Stumm, R. Plomin, Genetic Correlates of Psychological Responses to the COVID-19 Crisis in Young Adult Twins in Great Britain. Behav. Genet. 51, 110-124 (2021).

30. Rijksinstituut voor Volksgezondheid en Milieu, COVID-19 dataset (2021), (available at https://data.rivm.nl/covid-19/).

31. W. en S. Ministerie van Volksgezondheid, Vanaf 1 juni testen mogelijk voor iedereen met milde klachten - Nieuwsbericht - Rijksoverheid.nl (2020), (available at https://www.rijksoverheid.nl/actueel/nieuws/2020/05/27/vanaf-1-juni-testen-mogelijk-vooriedereen-met-milde-klachten).

32. K. McAllister, L. E. Mechanic, C. Amos, H. Aschard, I. A. Blair, N. Chatterjee, D. Conti, W. J. Gauderman, L. Hsu, C. M. Hutter, M. M. Jankowska, J. Kerr, P. Kraft, S. B. Montgomery, B. Mukherjee, G. J. Papanicolaou, C. J. Patel, M. D. Ritchie, B. R. Ritz, D. C. Thomas, P. Wei, J. S. 
Witte, Current Challenges and New Opportunities for Gene-Environment Interaction Studies of Complex Diseases. Am. J. Epidemiol. 186, 753-761 (2017).

33. M. Shi, K. M. O'Brien, C. R. Weinberg, Interactions between a Polygenic Risk Score and Nongenetic Risk Factors in Young-Onset Breast Cancer. Sci. Rep. 10, 3242 (2020).

34. A. Jolicoeur-Martineau, J. Belsky, E. Szekely, K. F. Widaman, M. Pluess, C. Greenwood, A. Wazana, Distinguishing differential susceptibility, diathesis-stress, and vantage sensitivity: Beyond the single gene and environment model. Dev. Psychopathol. 32, 73-83 (2020).

35. S. Scholtens, N. Smidt, M. A. Swertz, S. J. Bakker, A. Dotinga, J. M. Vonk, F. van Dijk, S. K. van Zon, C. Wijmenga, B. H. Wolffenbuttel, R. P. Stolk, Cohort Profile: LifeLines, a three-generation cohort study and biobank. Int. J. Epidemiol. 44, 1172-1180 (2015).

36. I. M. van Vliet, E. de Beurs, [The MINI-International Neuropsychiatric Interview. A brief structured diagnostic psychiatric interview for DSM-IV en ICD-10 psychiatric disorders]. Tijdschr. Voor Psychiatr. 49, 393-397 (2007).

37. the Haplotype Reference Consortium, A reference panel of 64,976 haplotypes for genotype imputation. Nat. Genet. 48, 1279-1283 (2016).

38. T. Ge, C.-Y. Chen, Y. Ni, Y.-C. A. Feng, J. W. Smoller, Polygenic prediction via Bayesian regression and continuous shrinkage priors. Nat. Commun. 10, 1776 (2019).

39. S. T. Sherry, dbSNP: the NCBI database of genetic variation. Nucleic Acids Res. 29, 308-311 (2001).

40. S. Purcell, C. Chang, PLINK 2.0 (www.cog-genomics.org/plink/2.0/).

41. C. C. Chang, C. C. Chow, L. C. Tellier, S. Vattikuti, S. M. Purcell, J. J. Lee, Second-generation PLINK: rising to the challenge of larger and richer datasets. GigaScience. 4 (2015), doi:10.1186/s13742-015-0047-8.

42. M. van B. Z. en Koninkrijksrelaties, Personal Records Database (BRP) - Personal data Government.nl (2017), (available at https://www.government.nl/topics/personaldata/personal-records-database-brp).

43. Landelijk Coördinatiecentrum Patiënten Spreiding, Datafeed. LCPS (2021), (available at https://lcps.nu/datafeed/).

44. T. Hale, N. Angrist, R. Goldszmidt, B. Kira, A. Petherick, T. Phillips, S. Webster, E. CameronBlake, L. Hallas, S. Majumdar, H. Tatlow, A global panel database of pandemic policies (Oxford COVID-19 Government Response Tracker). Nat. Hum. Behav. (2021), doi:10.1038/s41562-02101079-8.

45. COVID-19 Community Mobility Report. COVID-19 Community Mobil. Rep. (2021), (available at https://www.google.com/covid19/mobility).

46. The Royal Netherlands Meteorological Institute, KNMI - Daggegevens van het weer in Nederland (2021), (available at https://www.knmi.nl/nederlandnu/klimatologie/daggegevens).

47. J. Pinheiro, D. Bates, S. DebRoy, D. Sarkar, R Core Team, nlme: Linear and Nonlinear Mixed Effects Models (2021; https://CRAN.R-project.org/package=nlme).

48. R Core Team, $R$ : A language and environment for statistical computing ( $\mathrm{R}$ Foundation for Statistical Computing, Vienna, Austria, 2008; http://www.r-project.org), vol. 1 of $R$ Foundation for Statistical Computing.

49. D. Bates, M. Mächler, B. Bolker, S. Walker, Fitting Linear Mixed-Effects Models Using Ime4. J. Stat. Softw. 67, 1-48 (2015).

50. J. Hartung, Statistical meta-analysis with applications (Hoboken, N.J. : Wiley, 2008; http://archive.org/details/statisticalmetaa0000hart). 


\section{Acknowledgements}

625 L.F. is supported by grants from the Dutch Research Council (ZonMW-VIDI 917.14.374 and ZonMW-

$\mathrm{VICl}$ to L.F.) and by an ERC Starting Grant, grant agreement 637640 (ImmRisk) and through a Senior

627 Investigator Grant from the Oncode Institute. P.D. is supported by a grant from the Dutch Research Council (ZonMW-VENI to P.D.).

The Lifelines Biobank initiative has been made possible by funding from the Dutch Ministry of Health, Welfare and Sport, the Dutch Ministry of Economic Affairs, the University Medical Center Groningen (UMCG the Netherlands), the University of Groningen, the Northern Provinces of the Netherlands, FES (Fonds Economische Structuurversterking), SNN (Samenwerkingsverband Noord Nederland) and REP (Ruimtelijk Economisch Programma).

We acknowledge funding for the LifeLines Corona Research project from the University of Groningen and the University Medical Centre Groningen. The authors wish to acknowledge the efforts of the Lifelines Corona Research Initiative and th following initiatives participants: Pauline Lanting (4), Judith M. Vonk (1), Ilja Nolte (1), Anil P.S. Ori (4,5), Annique Claringbould (4), Floranne Boulogne (4), Marjolein X.L. Dijkema (4), Henry H. Wiersma (4), Robert Warmerdam (4), Soesma A. Jankipersadsing (4). Irene van Blokland $(4,7)$ Groningen, The Netherlands 

Groningen, Groningen, The Netherlands

7) Department of Cardiology, University of Groningen, University Medical Center Groningen, Groningen, The Netherlands

The generation and management of GWAS genotype data for the Lifelines Cohort Study is supported by the UMCG Genetics Lifelines Initiative (UGLI). The authors wish to acknowledge the services of the Lifelines Cohort Study, the contributing research centers delivering data to Lifelines, and all the study participants. Lopera Maya (1), Ilja M Nolte (3), Serena Sanna (1), Harold Snieder (3), Morris A Swertz (1), Judith M Vonk (3), Cisca Wijmenga (1)

662 2) Department of Pediatrics, University of Groningen, University Medical Center Groningen, The 663 Netherlands 3) Department of Epidemiology, University of Groningen, University Medical Center Groningen, The Netherlands

We thank the UMCG Genomics Coordination Center, the UG Center for Information Technology and their sponsors BBMRI-NL \& TarGet for storage and compute infrastructure.

We thank Katherine Mclntyre for the English editing of our manuscript.

\section{Author contributions}



contributed to questionnaire related data collection, provided critical input and edited the

674 manuscript.

\section{Competing interests}

676 The authors declare no competing interests.

\section{Materials \& Correspondence}

678 Correspondence should be addressed to Lude Franke, I.h.franke@umcg.nl 